\title{
Reasons for knitting blogging and its importance for crafting
}

\author{
Katja Vilhunen, Sinikka Pöllänen and Harri Pitkäniemi
}

The purpose of this study was to describe the reasons for knitting blogging and the importance of blogging for the bloggers' crafting. A multiphase mixed-methods study focusing on quantitative research methods was the methodological basis. Therefore, the study included both sequential and simultaneous investigation paths. In this study, the quantitative data were collected from the same group of Finnish knitting bloggers by two online surveys in $2008(N=501)$ and in $2013(N=212)$. The quantitative data focused on time-related changes in blogging, whereas the qualitative data, collected by essays $(N=50)$ during 2013-2014, was used to explain the quantitative data. In quantitative analysis, the key features of reasons for knitting blogging were analysed by principal component analysis. The differences in the principal components for the background groups between the surveys were elucidated by means of 2-way analysis of variance. The qualitative data were analysed by data-driven content analysis. The results indicated that there were several reasons for knitting blogging. According to the results, the elements of knitting blogging were: 1) inspiration and materialization, 2) connecting and community support, 3) encouragement and 4) reflection and reminiscence. Knitting blogging has reshaped crafting by combining the material and tactile process of knitting with digital practices of lifestreaming and with participatory activities in networked spaces. It appeared that knitting and blogging complemented each other, and that blogging supported development of the blogger's crafting into a serious leisure activity with meaningful long-term activities and clear goals.

Keywords: digital practices, knitting blog, leisure, mixed methods design, online communities

\section{Introduction}

During the twenty-first century crafting, especially hand knitting, has been revived among women of different ages and for different reasons throughout the Western world (e.g., von Busch, 2010; Croghan, 2013; Hemmings, 2010; Kouhia, 2015; Stannard \& Sanders, 2015). Knitting can be a short-term pleasurable activity that can be done with little practice (Dirix, 2004; Turney, 2009) and following ready-made instructions and patterns (Pöllänen, 2015). On the other hand, it can be a serious leisure (Court, 2020; Stebbins, 2015) requiring perseverance, creativity and long-term work based on considerable skill, knowledge and experience.

Several international researchers (e.g., Corkhill, Hemmings, Maddock, \& Riley, 2014; Hackney, 2013; Kouhia, 2015; Riley, Corkhill \& Morris, 2013; Turney, 2009) have demonstrated that many people find knitting to be an individually pleasing activity and one which may enhance well-being. As a hobby, crafting serves as a means of self-expression and increases self-awareness, self-esteem and independence according to the hobby's own goals (Pöllänen, 2013). Matthews (2016) and Pöllänen and Voutilainen (2017) noted that contemporary crafting, like knitting, is an attempt to occupy the present differently. It resembles certain practices of mindfulness in daily life, but may also be a means to get time for oneself, without the involvement of activities outside the domestic domain. Creating with the hands and having one's own time without haste or obligations has often been the most important driving factor, although the knitting process does usually lead to a concrete end product (Johnson \& Wilson, 2005; Kouhia 2015; Mason, 2005; Pöllänen, 2015). 
Textile crafting has been reported to be a relaxing and reflexive activity that is born of love for materials and connection with other crafters and like-minded people (Kenning, 2015; Mason, 2005; RusiñolRodriguez, Rodriguez-Bailon, \& Ramon-Aribau, 2020; Schofield-Tomschlin \& Littrell, 2001). Knitting is seen as part of a wider process of connecting individual creativity and leisure practices with collective activities and broader networks of craft culture (Court, 2019; Gauntlett, 2018; Kouhia, 2020). In this way, knitting engages the enthusiast in new challenges and in social groups, events, networks, organizations and social relationships, with the benefits of meeting people and making new friends (Stebbins, 2001).

The resurgence of crafting has connected expression to new technological tools (see Bratich \& Brush, 2011; Winge \& Stalp, 2013). Through the rise of Internet and virtuality, there is a growing presence of knitting in the web, including, for example, blogs and social networking sites, connecting a global community of knitters (Gauntlett, 2018; Orton-Johnson 2014). As Orton-Johnson (2014) reports, virtual networks and environments have reshaped the stereotype of knitting as a leisure activity in a fundamental manner: technology provides a reciprocal and interconnected context for knitting in which the distinctions between leisure and technology are increasingly blurred.

A growing body of diverse international research about knitting has been concentrated on subjective well-being (e.g., Brooks, Ta, Townsend, \& Backman, 2019; Corkhill et al., 2014; Lamont \& Ranaweera, 2019; Parkins, 2004; Riley, 2008; Riley et al., 2013; Rosner \& Ryokai, 2009; Schofiled-Tomschin \& Littrell, 2001), and on the perspective of serious leisure (Court, 2020) and DIY culture (e.g., von Busch, 2010; Farinosi \& Fortunati, 2018; Gauntlett, 2018; Kelly, 2014; Kouhia 2015; Wolf \& McQuitty, 2011). In addition, craft has also been studied to an increasing extent as a basis for personal, social or political change via new materiality (e.g., Corkhill et al., 2014; Greer, 2008; Hosegood, 2009; Minahan \& Cox, 2011; Myzelev, 2006, 2015; O`Donald, Hatza, \& Springgay, 2010; Springgay, 2010), and in craft web cultures as a basis for knitting as a feminist project (e.g., Humphreys, 2008; O’Donald et al., 2010; Minahan \& Cox, 2007). Earlier studies have emphasized the meaning of crafting as a hobby practiced alone at home (Pöllänen, 2015; Kouhia, 2015; Pöllänen \& Voutilainen, 2017), and a number of studies have also looked at the interactions within knitting groups in face-to-face contexts (e.g., Prigoda \& McKenzie, 2007). However, research has demonstrated (e.g., Kouhia, 2020; Orton-Johnson, 2004; Wei, 2004) that digitalization has revolutionized hobbyist crafting significantly, for example, offering new tools and ways to engage in crafting. In this regard, the research on blogging has not been focused on the blogs maintained by ordinary craft hobbyists, although blogs began to become part of handicrafts in the early 21 st century, when they rapidly gained popularity among knitters. The research has not elucidated the attractiveness of blogs as a combination of crafting and online communities or the importance of the blog as part of crafting as a leisure activity. Thus, the purpose of this study is to describe the reasons for knitting blogging and the importance of blogging for the bloggers' crafting.

\section{Knitting in networked spaces}

According to von Busch (2010), craft has traditionally been positioned as the opposite of technology, but today home-based practices are extended with the possibilities of new technologies (Greer, 2008). The new articulations and free creativity in amateur crafts have brought knitting away from private homes and into the public domain of the Internet (Haveri, 2016; Myzelev, 2015; see Lenhart \& Fox, 2006; Papacharissi, 2007). The Internet has opened up a world of imagination and participation in crafts, where craft makers can create content and messages, and thus are not just followers; they are active publishers and participators (Gauntlett, 2018; Kouhia, 2020). Orton-Johnson (2014) observed that this kind of participatory web culture-based leisure has reshaped the experience of knitting, by combining the material and tactile process of knitting with the digital practices of life-streaming. 
Knitters can share stories about their own craft activities with the public in a large on-line community (Haveri, 2016), for example, via frequently modified web pages, blogs (Herring, Scheidt, Bonus, \& Wright, 2004). The knitters photograph, blog and chat about their knitting projects and yarns, but they also follow other recognized bloggers, exchange patterns and share their expertise (Orton-Johnson, 2014). Usually, the majority of blogs are of the personal journal type (Schmidt, 2007), aiming towards self-expression (McCullagh, 2008). Among the first related studies, Wei (2004) found that there are similarities in knitting blog contents. Since then, research has shown that on a general level there are differences in the use of blogs between countries, ages and genders (Pedersen, 2010; Trammell, Tarkowski, Hofmokl, \& Sapp, 2006; Herring, Scheidt, Wright, \& Bonus, 2005; Schaap, 2004). However, blogs are found to be an ideal medium for the process of thinking (Boyd, Gorham, Justice, \& Anderson, 2013) and materialization, providing the opportunity of working through unfinished ideas and failed processes (Kouhia, 2020). Blogging has given knitters new ways to think about and engage with their craft, and ultimately, blogging has become an embedded part of craft practicing itself (OrtonJohnson, 2014; see Miura \& Yamashita, 2007). In this regard, blogging helps crystallise the knitter's ideas and skills into something special and noteworthy, and thus to gain feedback and social status (Haveri, 2016; Nardi, Schiano, Gumbrecht, \& Swartz, 2004).

Social media has become a part of crafting not only in the information retrieval and online presentation of own crafts, but also in the discovery of a group of like-minded crafters (Kouhia, 2020; Kuznetsov \& Paulos, 2010; Torrey, Churchill, \& McDonald, 2009). Gauntlett (2018) observed that through creating and sharing their projects, individuals feel engaged and connected with their physical environment and the social world. For example, social media binds knitters into a global community that provides support and resources for crafting that invest it with meaning. Due to the networked spaces, crafting has become renewed in the form of information networks providing different ways for reciprocal communication, for both the production and consumption of crafts (Orton-Johnson, 2014; Torrey et al., 2009). The maintenance of blogs and participation in dialogue have led readers with the same passion and interest towards social interaction, and thereby given rise to the emergence of veritable blog networks and virtual communities (Pedersen, 2010; Orton-Johnson, 2014; Rosner \& Ryokai, 2009; Schmidt, 2007). Thus, despite the lack of close contact, the new digital tools and technologies have helped create vivid, inspiring and empowering craft communities and offered new ways for practising creative skills, which has also had a significant impact on hand crafters' engagements with crafted objects and materials (Greer, 2008; Kouhia, 2020; Waterhouse, 2010). Clearly, as Kouhia (2020) noted, digital-material interactions as a whole indicate how the digital aspect emerges as a part of crafting, and how crafting itself has become digital - also in knitting blogging.

\section{Methodology}

\section{Method and data collection}

The purpose of this study is to describe the reasons for knitting blogging and the importance of blogging for the hobbyists' crafting. The methodological basis of the study lies in pragmatism, which is based on the proposition that researchers should use methods, techniques and procedures that work best for the particular research problem being investigated (Teddlie \& Tashakkori, 2009). Thereby, in order to get the best possible understanding of the topic and to reach the research aim, this work was based on a multiphase mixed-methods study focusing on quantitative research methods. The study included both sequential and simultaneous investigation paths. Mixed-methods can potentially have several different research purposes for mixing quantitative and qualitative data, but in this study they were especially (a) triangulation, in which the intent is to seek convergence in data, and (b) complementarity, in which the intent is to measure overlapping but different facets of a phenomenon (see Greene, Caracelli, \& Graham, 1989). 
The study consists of two quantitative data sets and one qualitative set and, ultimately, the findings of this mixed-methods study constitute a harmonious whole. The starting point of the study was the first questionnaire in 2008, which was later augmented with both qualitative and quantitative follow-up information. The whole data was collected from the same target group of Finnish knitting bloggers. Quantitative data were collected by two on-line surveys, the first in May $2008(\mathrm{~N}=501)$ and the second in May 2013 (N=212). The request to participate in the questionnaire was published through the Finnish Knitting Blogs -site and distributed to all active blogs in that site by using the blog's commenting feature. In the quantitative survey, the reasons for the craft hobbyist maintaining a knitting blog were asked with eight 7-stage Likert questions, and the importance of blogging for making crafts was asked with 11 questions. The background questions concerned general information about the participant's blogging activities (e.g., commenting, participating in on-line knitting meetings and events) and crafting.

The qualitative data was collected by essays $(\mathrm{N}=50)$ during 2013-2014 in order to explain the quantitative data. The participants' willingness to participate in the further study was asked at the end of the second survey. Thus, those who responded positively were sent a request to write an essay. Participants were especially asked to write about their craft making and tell how blogging was a part of it. The aim of this qualitative data was to verify the results of the quantitative analysis through individual accounts. We believe that this will increase the validity of this study, because to some extent the qualitative study offers a level of understanding which the quantitative instrument with pre-prepared questions and statistical analyses is unable to provide (see Creswell \& Plano, 2018). Thus, the idea behind the use of both quantitative and qualitative data and mixed-methods research was to improve trustworthiness and triangulation and to obtain a more complete picture of the phenomenon of knitting blogging than is possible with a narrower methodological approach (see Teddlie \& Tashakkori, 2009).

\section{Data analysis}

In this study, the complementarity with quantitative and qualitative data sought to elaborate and clarify the results from one (quantitative) method with those from the other (qualitative) method. Thus, as a sequential mixed method study (Teddlie \& Tashakkori, 2009), the quantitative data were refined with qualitative data at the end of the analysis process. The results obtained from the qualitative data of knitting blogging were used to explain the quantitative results, and finally the results obtained from different materials were compared with each other.

The quantitative data were compounded during the analysis, but the qualitative data were analysed separately. In quantitative analysis, the key features of reasons for knitting blogging were analyzed by principal component analysis. The analysis was performed separately for eight reasons that dealt with blogging, and for 11 descriptions of the importance of knitting blogging for the blogger's craft making. In principal component analysis, finding a new set of variables smaller than the original set of variables, only one solution in the analysis was accepted. In this solution, the value of the Kaiser test was greater than 0.5 , the Bartlet's sphericity test was statistically very significant $(\mathrm{p}<0.001)$, and communality was $>0.400$ (see Dunteman, 1989), which all confirms that the result of the principal component analysis predicted statistically well the value of the solution containing most of the information in the large set. The differences in the principal components for the background groups between the surveys were elucidated by means of 2-way analysis of variance (see Kaplan, 2004). Changes between the data of questionnaires in knitting blogging were examined using the independent samples t-test (see Kaplan, 2004). With regard to knitting blogging, there were 21 categories (see Table 1), in which the reasons for knitting blogging are marked with the abbreviation pt and the significance of the knitting blog for crafting with the abbreviation mk. The number after pt and $\mathrm{mk}$ refers to which proposition in the surveys dealt with the same subject. 
Table 1. Categories of knitting blogging

\begin{tabular}{|c|c|c|c|c|c|}
\hline $\begin{array}{l}\text { Knitting blogging } \\
\text { category }\end{array}$ & $\mathrm{N}$ & question & category & $\mathrm{N}$ & question \\
\hline Notebook & 58 & pt8 & Publicity & 11 & $\mathrm{pt} 3$ \\
\hline Connection to other bloggers & 48 & $\mathrm{pt} 2+4$ & Making together & 11 & $\mathrm{mk} 4$ \\
\hline Presentation of manufactured products & 46 & pt7 & Help & 10 & $\mathrm{mk} 8$ \\
\hline Readers & 40 & pt1 & Demonstration of skills & 10 & pt7 \\
\hline Information & 37 & $\mathrm{mk} 1+11, \mathrm{pt} 4$ & Other meaning & 7 & \\
\hline Ideas & 24 & $\mathrm{mk} 2$ & $\begin{array}{l}\text { Connection with friends and } \\
\text { family }\end{array}$ & 7 & pt6 \\
\hline Communality & 22 & & Knitting meetings & 6 & \\
\hline Seeing what others do & 19 & $\mathrm{mk} 10$ & Knitting events & 6 & mk9 \\
\hline To keep the hobby alive & 17 & $\mathrm{mk} 5$ & Charity & 5 & mk6 \\
\hline $\begin{array}{l}\text { Change in craft making after starting } \\
\text { blogging }\end{array}$ & 17 & & Self-expression & 4 & pt5 \\
\hline Feedback & 17 & $\mathrm{mk} 3+7$ & & & \\
\hline
\end{tabular}

The qualitative data were analysed inductively by data-driven content analysis. In this case, there was no predetermined set of criteria or theoretical premises at the beginning of the process (see Thomas, 2003). The purpose in the analysis was to deepen the information obtained from the survey and to confirm the core reasons for knitting blogging and the importance of blogging for the hobbyists' crafting through classification and descriptive codes. Thus, the qualitative results confirmed the quantitative results, but most importantly, they gave the participants' voice and life to the text in a way that the quantitative results could not.

\section{Results}

\section{Reasons for knitting blogging}

Principal component analysis explains $70 \%$ of the reasons for knitting blogging in both parts of the quantitative data $(\mathrm{N}=713)$. The main components and their variation in the data were: blogging activity $(24.96 \%)$, self-expression and presentation of crafts (17.49\%), connecting friends and family (13.95 $\%)$ and notebook (13.62 \%) (see Table 2). The model fits the data well $\left(x^{2}(28)=834.01, \mathrm{KMO}=0.687, \mathrm{p}<0.001\right)$. 
Table 2. Reasons for knitting blogging

\begin{tabular}{|c|c|c|c|}
\hline $\begin{array}{l}\text { Principal component } \\
\text { and eigenvalue }\end{array}$ & Questions & $\begin{array}{l}\text { Cumu- } \\
\text { lative }\end{array}$ & $\begin{array}{l}\text { Component } \\
\text { loading }\end{array}$ \\
\hline $\begin{array}{l}\text { Blogging activity } \\
\text { Eigenvalue: } 2.490\end{array}$ & $\begin{array}{l}\text { 1. I keep a knitting blog to get readers. } \\
\text { 2. I keep a knitting blog to be in touch with other bloggers } \\
\text { (help, tips, advice, comments). } \\
\text { 3. I keep a knitting blog to get attention/fame. } \\
\text { 4. I keep a knitting blog to share information and to } \\
\text { organize information found on the internet. }\end{array}$ & $\begin{array}{l}0.721 \\
0.624 \\
0.668 \\
0.501\end{array}$ & $\begin{array}{l}0.746 \\
0.734 \\
0.642 \\
0.621\end{array}$ \\
\hline $\begin{array}{l}\text { Self-expression and } \\
\text { presentation of } \\
\text { crafts } \\
\text { Eigenvalue: } 1.101\end{array}$ & $\begin{array}{l}\text { 5. I keep a knitting blog to express myself. } \\
\text { 7. I keep a knitting blog to show others my handicrafts, } \\
\text { parts of my knitting process and techniques that I use. }\end{array}$ & $\begin{array}{l}0.756 \\
0.671\end{array}$ & $\begin{array}{l}0.848 \\
0.733\end{array}$ \\
\hline $\begin{array}{l}\text { Connecting friends } \\
\text { and family } \\
\text { Eigenvalue: } 1.031\end{array}$ & $\begin{array}{l}\text { 6. I keep a knitting blog to be in contact with my friends } \\
\text { and family (rather than other knitting bloggers). }\end{array}$ & 0.857 & 0.918 \\
\hline $\begin{array}{l}\text { Notebook } \\
\text { Eigenvalue: } 0.978\end{array}$ & $\begin{array}{l}\text { 8. I keep a knitting blog to see what kind of craft I have } \\
\text { made and to save information about different parts of } \\
\text { the knitting process so I can remember it better, for } \\
\text { example, decreasing, changes in the model and density } \\
\text { of the knitting. }\end{array}$ & 0.804 & 0.887 \\
\hline
\end{tabular}

The main reason for knitting blogging was the interest in blogging itself as an activity. Blogging was most of all about writing a blog for the blogger herself, rather than for the readers. Beyond a place to document and compile a notebook of the knitting history, for bloggers themselves it was important to organize and share knitting-based information that was found on the Internet. However, most of the information shared and arranged was self-made and was eventually intended to be notes for the bloggers themselves. Nevertheless, according to blogging etiquette, it was important to provide inspiration about materials and techniques, as well as information about the original source of the craft project to share them with other bloggers.

On the other hand, blogging served as a forum for receiving feedback and reputation. According to the 2 -way analysis of variance, blogging was considered even more important in both surveys if the blogger commented often on others' blogs $\left(F_{3,705}=12.24, \mathrm{p}<0.001, \mathrm{n}_{p}^{2}=0.05\right)$. Bloggers kept in touch with other knitting bloggers through the blog by commenting and following each other's blogs. The bloggers reported that it was motivating if they had an audience reading and responding to their writings. Therefore, the bloggers were interested in their followers, blog visitors and written comments. Comments, for example about yarns and stores, encouraged them to ask for advice and improve knitted objects and to solve problems encountered during the knitting process. Although the blogs served as a notebook for the bloggers themselves, they took their readers into consideration when they were writing or planning to write a post on their knitting blog. The qualitative analysis indicated that for the bloggers, the readers were the main motivation to finish their handicrafts. In fact, the blog served as an incentive for crafting as a long-term activity, as the bloggers also described their unfinished works in their writings. As a result, maintaining a blog obliged the bloggers to actively describe their crafting. 
Sometimes keeping a blog inspires me to finish my handicraft so that I can get some content to the blog for my readers. It is important to write a post on the blog at an even pace, so the readers do not get bored or lose interest in my blog. For the same reason I can start a quick craft project or clean up my yarn draw or post a writing about my unfinished objects. (B27, 24 years, groups beginner, blog age 1-2 years)

The second main reason for knitting blogging was self-expression and presentation of crafts, mostly of self-crafted manufactured products. This reason for blogging had become even more important between surveys $(\mathrm{t}(711)=2.85, \mathrm{p}=0.004)(\mathrm{d}=0.234)$. The participants felt that self-expression and presentation of crafted products were more important for their blogging in 2013 than in 2008. Clearly, writing the blog itself also served as one means of self-expression. The analysis showed that creating a blog post was considered as a creative process and it was done with a great deal of care. Through the blog, the bloggers were able to display their finished handicrafts and crafting skills. Eventually, blogs were open portfolios that were resumed via an on-line medium. Over the years, for some of the bloggers their knitting blog had become an important way to present their handicrafts to potential customers, also for international contacts and trading outside Finland. The essays revealed, however, that most important for the bloggers was being a talented craft maker who receives recognition from other people.

I could not be myself without my knitting blog. Without my blog I would have never designed knitteds that would be published all over the world. I would not have got to know talented and famous knitting designers, the best yarn houses and fashion journal experts. Even though I am a nobody from Eastern Finland, I have received an amazing opportunity to work with the best of the knitting world. My blog is my curriculum vitae for the outside world. I am not sure that I could ever earn my living just doing handicrafts, but it is nice to know that it might be possible. (B42, 37 years old, typical member of the group, blog age over 6 years)

The third reason for knitting blogging was connecting friends and family. This had become even more important between the surveys $(\mathrm{t}(711)=3.52, \mathrm{p}<0.001)(\mathrm{d}=0.289)$. In addition to introducing their crafted products, the bloggers were updating their own and family affairs as well as their everyday events. For some of the bloggers this was one way of keeping in touch with family members and friends.

My blog started as a craft blog but it has changed to telling relatives how I am doing. (B7, 28 years old, sometimes part of the group, blog age 3-5 years)

The fourth reason for knitting blogging was continuous hosting of the notebook. Therefore, for updating their postings the bloggers made accurate notes of completed crafts and observations during the knitting process. Some of the bloggers had been handwriting a notebook before blogging, and thus blogging changed the traditional notebook into an on-line medium. For the bloggers themselves, writing a notebook was also a way to think back on what they had previously crafted. According to the essays, the bloggers' own texts and photographs helped them to remember and reflect on their feelings during the knitting process and, more importantly, to see the improvement of their own skills over the years and in cases when they had given their crafted products as gifts to others.

I give most of my handicrafts as presents and the rest of the craft are in use... My knitting blog is for me some kind of knitting diary where I can save a photograph of all my finished handicrafts - so I can later remember what I have actually been doing. (B48: 30 years old, typical member of the group, blog age over 6 years)

\section{The importance of blogging for crafting}

Principal component analysis explains $67.35 \%$ of the importance of blogging for the hobbyist crafting in both of the quantitative data sets $(\mathrm{N}=713)$. On the basis of the analysis, the main components of the data and their variation were: knowledge, ideas and help (31.83\%), participation and togetherness $(18.41 \%)$ and feedback $(17.11 \%)$ (see Table 3$)$. The model fits the data well $\left(x^{2}(55)=3377.69\right.$, $\mathrm{KMO}=0878, \mathrm{p}<0.0012017)$. 
Table 3. The importance of blogging for crafting

\begin{tabular}{|c|c|c|c|}
\hline $\begin{array}{l}\text { Principal component } \\
\text { and eigenvalue }\end{array}$ & Questions & $\begin{array}{l}\text { Cumu- } \\
\text { lative }\end{array}$ & $\begin{array}{l}\text { Componen } \\
\text { t loading }\end{array}$ \\
\hline $\begin{array}{l}\text { Knowledge, ideas and } \\
\text { help }\end{array}$ & $\begin{array}{l}\text { 1. Through/with the help of a blog I can get information } \\
\text { about knitting techniques and different ways to knit. }\end{array}$ & 0.725 & 0.836 \\
\hline \multirow[t]{5}{*}{ Eigenvalue: 4.902} & $\begin{array}{l}\text { 11. Through a blog I can get information that I can't get } \\
\text { from a ready-made pattern (for example seeing a } \\
\text { model made of different yarns) }\end{array}$ & 0.718 & 0.832 \\
\hline & $\begin{array}{l}\text { 2. Through blogs I can find the newest knitting models } \\
\text { and knitting ideas. }\end{array}$ & 0.679 & 0.815 \\
\hline & $\begin{array}{l}\text { 10. Through blogs I can see what other knitting bloggers } \\
\text { are doing. }\end{array}$ & 0.688 & 0.772 \\
\hline & 5. Knitting blogs keep my knitting hobby alive. & 0.568 & 0.595 \\
\hline & $\begin{array}{l}\text { 8. Through blogs I can get help and ask advice for my } \\
\text { craft making. }\end{array}$ & 0.634 & 0.573 \\
\hline $\begin{array}{l}\text { Participation and } \\
\text { togetherness }\end{array}$ & $\begin{array}{l}\text { 6. Through blogs I can participate in charity just as } \\
\text { knitting to disadvantaged people. }\end{array}$ & 0.669 & 0.801 \\
\hline \multirow[t]{3}{*}{ Eigenvalue: 1.496} & $\begin{array}{l}\text { 9. Through my blog I can regularly participate in knitting } \\
\text { events that are being held in other knitting blogs. }\end{array}$ & 0.648 & 0.799 \\
\hline & $\begin{array}{l}\text { 4. Knitting blogs capture the feeling of doing things } \\
\text { together in a handicraft class. }\end{array}$ & 0.440 & 0.509 \\
\hline & $\begin{array}{l}\text { 8. Through a knitting blog I can get help and ask for } \\
\text { advice for the making of handicraft works. }\end{array}$ & 0.643 & 0.501 \\
\hline \multirow[t]{2}{*}{ Feedback } & $\begin{array}{l}\text { 3. Through blogs I can get appreciation for my handicraft } \\
\text { and my knitting skills. }\end{array}$ & 0.826 & 0.895 \\
\hline & 7. Through blogs I can get feedback from my handicraft. & 0.804 & 0.808 \\
\hline
\end{tabular}

Considering craft making, the most obvious role of the blog was that it simplified the process of obtaining knowledge, ideas and help in situations in which craft was done at home alone. Above all, information retrieval and support were achievable at the knitter's own pace. However, this was considered to be more important in the first survey in 2008 than five years later in $2013(\mathrm{t}(711)=3.16$, $\mathrm{p}=0.002)(\mathrm{d}=0.259)$. Seeing other bloggers' knitted products was a good source of ideas and patterns. Additionally, the bloggers' own notes and photographs of products were described as inspiring media for new knitting processes. Through blogs, the bloggers obtained concrete information and skill-based knowledge about knitting techniques, for example, how to knit a particular pattern with a different yarn than in the model presented in the knitting magazine. The bloggers also wrote notes about their own crafting; about the yarns they used, the origin of the model, and about the changes they made to the original instructions. They also made a photo gallery of their knitted products. Thus, the blogs were concrete notebooks of the knitting-based materialization processes.

Both the quantitative and qualitative analysis also showed how important the blogging-based participation and togetherness was for the bloggers' crafting. For most of them, knitting had previously been an occasional hobby, but blogging inspired them to knit purposefully throughout the whole year. The nature of blogs as a socially interactive communication tool allowed the bloggers to express their frustrations and receive feedback that committed them to both crafting and blogging. Altogether, blogging deepened the blogger's hobby into a serious leisure activity with meaningful long-term objectives and clear goals in increasing one's craft making-related skills. 
I have learnt a lot about craft making through blogs. I learn about new techniques - like how to cast on and cast off a knitting. I have also learnt about new yarns and found out new places to buy them, but also about yarn ecology and so on. All this new information and learning new things have inspired me more and more, and the amounts of yarn I own have continued to grow. (B15: 43 years old, typical member of the group, blog age over 6 years)

In the 2-way analysis of variance in both surveys, it was found that participating and doing things together was more important if the blogger also participated in face-to-face knitting events $\left(F_{3,705}=19.30, \mathrm{p}<0.001, \mathrm{\eta}_{p}^{2}=0.08\right)$ or in blogging events $\left(F_{3,709}=54.29, \mathrm{p}<0.001, \mathrm{\eta}_{p}^{2}=0.07\right)$. For bloggers interested in charity crafts, the blog also provided an opportunity to participate in or organize charityrelated events. One of the bloggers even had her own separate blog for charity crafts. However, for most of the knitting bloggers, participating in knitting or charity events was not important for their blogging and crafting. Instead, for all the craft makers blogs provided an open channel for mutual help and advice and most often the comments allowed like-minded knitters to communicate together. In some cases, this led to pre-arranged face-to-face meetings. The qualitative analysis showed that participating and togetherness in an online community even approached the feelings of togetherness that were usually experienced in face-to-face handicraft groups. Eventually, some of the bloggers were crafting together only via the Internet.

At first it was very exciting and even addictive to participate in networking in the online community, and to create new relationships, and even to become friends. We have even been calling it an online sewing club. I get tips from others' crafts. I also get encouraging feedback when I show my crafts in my blog. It is usually a very positive thing. (B32: 61 years old, typical member of the group, blog age 1-2 years)

The bloggers' essays stressed the importance of the feedback they received on the blog for committing to their crafting. Friendly-toned comments, support and positive encouragement and the appreciation that was received from the other bloggers and followers about the crafted products and knitting skills were empowering and, thereby, they also committed the bloggers to both blogging and crafting when alone at home. Eventually, the nature of craft-making alone became a dialogical process with encouraging elements.

Making handicrafts is itself usually a bit lonely (not in a bad way but in the concrete sense that you are doing your craft alone), so it is nice when you have your own blog community to whom you can show your creations and get feedback well, usually praise) and ask advice when you have a problem and so on. (B48: 30 -years old, typical member of the group, blog age over 6 years)

\section{Discussion}

The merge between craft and digital mediations and online communities sheds light over how new tools and methods create new forms and reasons for crafting. According to the results, the reasons for knitting blogging and the importance of bloggers crafting can be grouped into elements of knitting blogging as follows: 1) inspiration and materialization, 2) connecting and community support, 3) encouragement and 4) reflection and reminiscence (see Figure 1). The importance of blogs for storing and handling information is well known from earlier studies (Blood, 2002; Pedersen, 2010). Thus, blogs are some kind of notebooks of inspiration and materialization of knitting ideas (see Gauntlett, 2018). Blogs were, as also noted by Schmidt (2007), personal journal-type writings and photo self-expressive postings of photographed self-crafted products (see also Lenhart \& Fox, 2006; Papacharissi, 2007). Blogs conveyed visual and verbal information about knitting techniques, yarns and their availability, and the sharing of practical material-based ideas, knowledge, and skills (see Lenhart \& Fox, 2006; Papacharissi, 2007; Torrey et al., 2009). The bloggers brought their knitting products from the physical world into the digital realm in the form of photos and posts (see Kouhia, 2020) of their knitting processes, experiences and views; their inspirations as well as their joy along with unfinished ideas and failed processes. As Haveri (2016) reported, blogging may crystallise the knitter's ideas and skills, gain feedback and, eventually, confirm social status through publishing. The results of this study revealed that the more active a blogger was, the more important part of crafting blogging they became. The findings also indicated that the role 
of blogging had changed over the years; in the beginning the blogs mainly provided technical help and advice, but later they were more a means of self-expression-based inspiration and materialization by which the bloggers presented their skills.

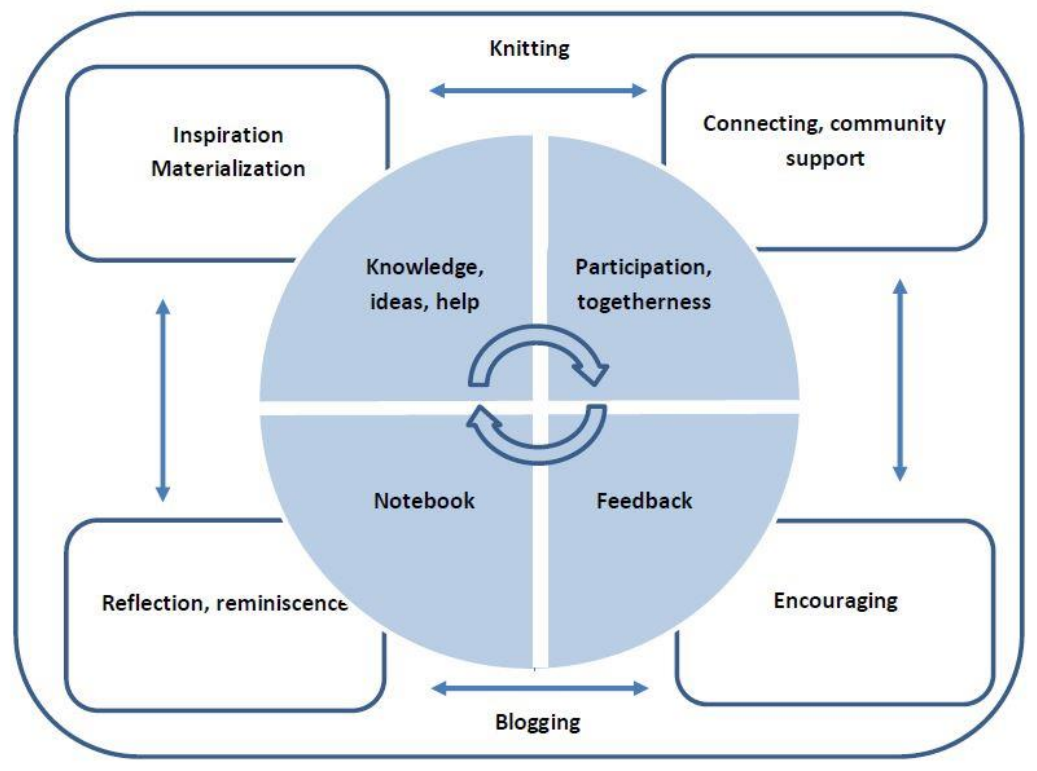

Figure 1. Elements of knitting blogging

The research results indicate that digital platforms such as blogs can connect crafters and transfer interactive craft knowledge and like-minded community support to an up-to-date context, which traditional craft knowledge sharing cannot always do (see Kouhia, 2020). As has also been noted in earlier studies, this kind of virtuality and connecting with other knitters, with the free use of online feedback, support and guidelines, motivates the web community (e.g., Gauntlett, 2018; Nardi et al., 2004; Orton-Johnson, 2014; Pedersen, 2010; Torrey et al., 2009) to continue their blogging (see Miura \& Yamashita, 2007). Through the knitting blog some of the bloggers participated in charity and knitting events with the same passion and interest in social interaction, increasing the feeling of working together despite long distances (see Kuznetsov \& Paulos, 2010; Orton-Johnson, 2014; Pedersen, 2010; Rosner \& Ryokai, 2009; Schmidt, 2007). According to the research results, connecting and community support in blogging encouraged the bloggers to continue crafting in the same vein as in face-to-face events (see Mason, 2005;_Rusiñol-Rodriguez et al., 2020; Schofield-Tomschlin \& Littrell, 2001).

Like knitting as an activity (e.g., Kouhia, 2015; Orton-Johnson, 2014), blogging was found to be an ideal medium for the processes of reflecting and reminiscence (see Boyd et al., 2013). Knitting bloggers were talented craft makers, who had the ability to make good use of their blog throughout the whole craft making process from the beginning until completion of the craft. Blogging provided knitters with new ways of thinking about and engaging in their craft, and ultimately blogging has become an embedded part of craft practicing itself (see Orton-Johnson, 2014). Thus, the digital word scaffolded the real-world crafting and vice versa. It can be perceived that both crafting and blogging have been serious leisure activities enhancing well-being (Stebbins, 2015), requiring perseverance, creativity and longterm work based on considerable skill, knowledge and knitting experience (Corkhill et al., 2014; Court, 2020; Pöllänen, 2015). Interestingly, as found in other studies (e.g., Lenhart \& Fox, 2006), earning extra income (see Pedersen, 2010) was not the main reason for knitting blogging. The results of the qualitative analysis confirmed that only a few of the participants took advantage of the financial potential of blogging or utilized their blog in their work. 
According to the research result, it can be concluded that blogging established knitting as part of a wider processes of meaningful production and connected the craft maker's individual leisure practices to collective activities and broader networks of craft culture (see Court, 2019; Gauntlett, 2018). Secondly, blogging was not only seen as participating and doing things together to establish various forms of hobby crafting for specialized communities of serious hobbyists (see Kouhia, 2020), but more widely, blogging was lifestyle documentation and construction and maintenance of relationships with friends and family members who were not insiders in blogging or knitting (b.f., Lenhart \& Fox, 2006; McCullagh, 2008; Nardi et al., 2004). Thus, in addition to knitting, blogging may also reinforce the overall well-being of the blogger, as research on crafts has shown (see Brooks et al., 2019; Corkhill et al., 2014; Lamont \& Ranaweera, 2019; Parkins, 2004; Pöllänen, 2015; Riley, 2008; Riley et al., 2013; Rosner \& Ryokai, 2009; Schofiled-Tomschin \& Littrell, 2001). Hence, knitting blogging has reshaped crafting by combining the material and tactile process of knitting with digital practices of life-streaming and with participatory activities in networked spaces (see Orton-Johnson, 2004). Notably, as Kouhia (2020) has pointed out, the digitalization may facilitate bringing something 'new' to the craft, but still the 'traditional' material context and tactile processes of crafting remain.

The results of this study can also be evaluated in terms of validity from the perspective of the methodology we used, mixed methods. Different validation frameworks are used in mixed methods, but here we utilized the method developed by Onwuegbuzie and Johnson (2006). They recommended that validity in mixed methods methodology be termed "legitimation", in order to utilize a bilingual nomenclature that can be used by both quantitative and qualitative researchers. This frame of reference is multifaceted, as the authors distinguish nine types of legitimation. We make use of it insofar as it is particularly suitable for assessing the legitimation (validity) of the research design according to this study. These types are sample integration legitimation, weakness minimization legitimation, sequential legitimation and commensurability legitimation.

Of these, (1) sample integration legitimation is pertinent in the way individuals and groups are chosen to be considered, and in the additional consideration of how to join different sets of people legitimately for making valid meta-inferences. The legitimation is increased in our study by the fact that the data was collected from the same target group three different times. The respondent groups were heterogeneous on the basis of background variables, so the results can be expected to describe knitting blogging from different perspectives and thus meet the requirement for consistency. (2) Weakness minimization legitimation means, as Onwuegbuzie and Johnson (2006, p. 58) write, “...the researcher must consciously and carefully assess the extent to which the weakness from one approach can be compensated by the strengths from the other approach and then plan and design the study to fulfill this potential; the researcher also must use this knowledge when combining, weighting, and interpreting the results. "In this study, both the quantitative and qualitative data yielded essentially similar findings (see Table 1, Methodology) and thus reinforce each other. Qualitative together with quantitative data provides a more diverse picture of the phenomenon, although at the same time the individual knitting bloggers talked about the results through their own experiences. 3) In this study, sequential legitimacy can be assessed on the basis of whether the qualitative approach brings something new or the same to the results of the quantitative analysis. The qualitative findings underline some of the same findings as the second phase of the quantitative part of the study. They open deeper intepretations of the phenomenon via the participants' comments in quotes. It would, of course, be interesting from the point of view of legitimacy to carry out a study to gather new data with a further developed research instrument based on an expanded and integrated understanding of the phenomenon. 4) In terms of commensurability legitimation, in general, we can evaluate the overall conception we get from the phenomenon under study. The methodologists Onwuegbuzie and Johnson (2006, p. 59) state that “...the mixed researcher must learn to make Gestalt switches from a qualitative lens to a quantitative lens, going back and forth, again and again." It is important that at all stages of the research, including planning, data collection, 
analysis and relating of findings to previous research literature, the aim is to focus on the phenomenon under study and not just to think through one of the (mono) methodological frameworks, more or less incompletely. In the discussion of our article, we have sought to relate the findings to previous studies - which also seeks to legitimize our findings. From the point of view of transferability to international research (e.g., Lomborg, 2009; Nardi et al., 2004; Wei, 2004), the findings can be compared to the similarities found in blogging; particularly the findings of Wein's (2004) research of knitting blogging are very similar to the results of this study. However, it must be taken into account that there are differences in the use of blogs between countries, ages, and genders (Herring et al., 2005; Pedersen, 2010; Schaap, 2004; Trammell et al., 2006).

The results of this study revealed that knitting and blogging complemented each other, and that blogging supported the blogger's crafting as a serious leisure activity (see Pöllänen, 2015). Above all it also enabled a new kind of participation and togetherness in the online community. Lately, as Kouhia (2020) has noted, the ways in which people engage with crafts in the digital world have diversified significantly. It appears that blogging was previously some kind of starting point for hobby crafts that was mediated via the Internet and with the aid of software. Therefore, because leisure activities are an increasingly important avenue for well-being promoters, there is a need to conduct further research to determine how new trends and technology-rich living styles also alter the nature of leisure-based craft making, and how the form and context change crafting as a hobby. It also appears that the number of blogs has decreased and that knitting bloggers have moved to the organizational community site Ravelry, which assembles knitters and crocheters together. Notably, crafting on online communities and networks via podcasts, social media and social tagging with various image services (e.g., YouTube, Flickr, Instagram, Pinterest, Twitter) deserves more consideration.

\section{References}

Blood, R. (2002). The weblog handbook: Practical advice on creating and maintaining your blog. Cambridge, MA: Perseus Publishing.

Boyd, A., Gorham, J., Justice, J., \& Anderson, J. (2013). Examining the apprenticeship of observation with preservice teachers: The practice of blogging to facilitate autobiographical reflection and critique. Teacher Education Quarterly, 40(3), 27-49.

Bratich, J. Z., \& Brush, H. M. (2011). Fabricating activism: Craft-work, popular culture, gender. Utopian Studies, 22(2), 233-260. https://doi.org/10.5325/utopianstudies.22.2.0233

Brooks, L., Ta, K. N., Townsend, A. F., \& Backman, C. L. (2019). “I just love it”: Avid knitters describe health and well-being through occupation'. Canadian Journal of Occupational Therapy, 86(2), 114-24. https://doi.org/10.1177/0008417419831401

von Busch, O. (2010). Exploring net political craft: From collective to connective. Craft Research, 1(1), 113124. https://doi.org/10.1386/crre.1.113 7

Corkhill, B., Hemmings, J. Maddock, A., \& Riley, J. (2014). Knitting and well-being. Textile: The Journal of Cloth and Culture, 12(1), 34-57. https://doi.org/10.2752/175183514x13916051793433

Court, K. (2019). Knitting two together (k2tog), "if you meet another knitter you always have a friend". Textile: The Journal of Cloth and Culture, 18(3), 278-291. https://doi.org/10.1080/14759756.2019.1690838

Court, K. (2020). A grounded theory approach to studying craft: The serious work and leisure of knitting. Craft Research, 11(1), 79-95. https://doi.org/10.1386/crre_00016_1

Creswell, J. W., \& Plano Clark, V. L. (2018). Designing and conducting mixed methods research. Thousand Oaks, CA: Sage.

Croghan, C. (2013). Knitting is the new yoga? Comparing techniques; physiological and psychological indicators of the relaxation response. Bachelor of Arts degree (Psychology Specialization) at DBS School of Arts Dublin, Department of Psychology DBS School of Arts.

Greene, J. C., Caracelli, V. J., \& Graham, W. F. (1989). Toward a conceptual framework for mixed-method evaluation designs. Educational Evaluation and Policy Analysis, 11(September), 255-274.

https://doi.org/10.3102/01623737011003255 
Greer, B. (2008). Knitting for good: A guide to creating personal, social, and political change stitch by stitch. Boston: Trumpeter.

Dirix, E. (2014). Stitched up - Representations of contemporary vintage style mania and the dark side of the popular knitting revival. Textile: Journal of Cloth and Culture, 12(1), 86-99. https://doi.org/10.2752/175183514x13916051793550

Dunteman, G. H. (1989). Principal component analysis. Series: Quantitative applications in social sciences. London: Sage. https://doi.org/10.4135/9781412985475

Farinosi, M., \& Fortunati, L. (2018). Knitting feminist politics: Exploring a yarn-bombing performance in a postdisaster city. Journal of Communication Inquiry, 42(2), 138-165. https://doi.org/10.1177/0196859917753419

Gauntlett, D. (2018). Making is connecting. The social power of creativity, from craft and knitting to digital everything. Cambridge, UK: Polity Press.

Hackney, F. (2013). Quiet activism and the new amateur: The power of home and hobby crafts. Design and Culture, 5(2), 169-193. https://doi.org/10.2752/175470813X13638640370733

Haveri, M. (2016). Pehmeä taide. [Soft art]. Helsinki: Maahenki.

Hemmings, J. (2010). In the loop: Knitting now. London: Black Dog Publishing.

Herring, S. C., Scheidt, L. A., Bonus, S., \& Wright, E. (2004). Bridging the gap: A genre analysis of weblogs. Proceedings of the Thirty-seventh Hawaii International Conference on System Sciences HICSS-37 (p. 11).

Big Island, HI, USA. Los Alamitos: IEEE Press. https://doi.org/10.1109/HICSS.2004.1265271

Herring, S. C., Scheidt, L. A., Wright, E., \& Bonus, S. (2005). Weblogs as a bridging genre. Information Technology \& People, 18(2), 142-171. https://doi.org/10.1108/09593840510601513

Hosegood, B. (2009). Whip your hobby into shape: Knitting, feminism and construction of gender. Textile: The Journal of Cloth and Culture, 7(2), 148-63. https://doi.org/10.2752/175183509X460065

Humphreys, S. M. (2008). The challenges of intellectual property of users' social networking sites: A case study of Ravelry. Proceedings of the $12^{\text {th }}$ international conference on entertainment and social media in the ubiquitous era, MindTrek '08 (pp. 125-130). Tampere: Finland. https://doi.org/10.1145/1457199.1457227

Johnson, C. J., \& Wilson, L. E. (2005). 'It says you really care': Motivational factors of contemporary female handcrafters. Clothing \& Textiles Research Journal, 23(2), 115-130. https://doi.org/10.1177/0887302X0502300205

Kaplan, D. (2004). The Sage handbook of quantitative methodology of social sciences. London: Sage. https://doi.org/10.4135/9781412986311

Kelly, M. (2014). Knitting as a feminist project? Women's Studies International Forum, 44(1), 133144. https://doi.org/10.1016/j.wsif.2013.10.011

Kenning, G. (2015). Fiddling with treads: Craft-based textile activities and positive well-being. Textile: Journal of Cloth and Culture, 13(1), 50-65.

Kouhia, A. (2015). The making-of: An autoethnographic cinema on the meanings of contemporary craft practicing for a young hobbyist. Textile: Journal of Cloth and Culture, 13(3), 266-283. https://doi.org/10.1080/14759756.2015.1084788

Kouhia, A. (2020). Online matters: Future visions of digital making and materiality in hobby crafting. Craft Research, 11(2), 261-273. https://doi.org/10.1386/crre 00028_1

Kuznetsov, S., \& Paulos, E. (2010). Rise of the expert amateur: DIY projects, communities, and cultures. Proceedings of the 6th Nordic Conference on Human-Computer Interaction: Extending Boundaries, NordiCHI'10 (pp. 295-304). Accessed 18 November 2018 from http://www.staceyk.org/hci/KuznetsovDIY.pdf https://doi.org/10.1145/1868914.1868950

Lamont, A., \& Ranaweera, N. A. (2019). Knit one, play one: Comparing the effects of amateur knitting and amateur music participation on happiness and wellbeing. Applied Research in Quality of Life, 15(1), 13531374. https://doi.org/10.1007/s11482-019-09734-z

Lenhart, A., \& Fox, S. (2006). Bloggers: A portrait of the Internet's new storytellers. Washington, DC: Pew/Internet \& American Life Project.

Lomborg, S. (2009). Navigating the blogosphere: Toward a genre-based typology of weblogs. First Monday, 14(5). Retrieved from https://journals.uic.edu/ojs/index.php/fm/article/view/2329/2178 https://doi.org/10.5210/fm.v14i5.2329 
Mason, R. (2005). The meaning and value of home-based craft. International Journal of Art \& Design Education, 24(3), 261-268. https://doi.org/10.1111/j.1476-8070.2005.00449.x

Matthews, R. (2016). The mindfulness in knitting. Meditations of craft and calm. Brighton: Leaping Hare Press.

McCullagh, K. (2008). Blogging: Self-presentation and privacy. Information \& Communications Technology Law, 17(1), 3-23. https://doi.org/10.1080/13600830801886984

Minahan, S., \& Wolfram Cox, J. (2007). Stitch'nBitch cyberfeminism, a third place and the new materiality. Journal of Material Culture, 12(1), 5-21. https://doi.org/10.1177/1359183507074559

Minahan, S., \& Wolfram Cox, J. (2011). The inner nana, the list mum and me: Knitting identity. Material Culture Review/Revue de la culture matérielle, 72, 38-50.

Miura, A., \& Yamashita, K. (2007). Psychological and social Influences on blog writing: An online survey of blog authors in Japan. Journal of Computer-Mediated Communication, 12(4), 1452-1471. https://doi.org/10.1111/j.1083-6101.2007.00381.x

Myzelev, A. (2006). Whip your hobby into shape: Knitting, feminism, and construction of gender. Textile: The Journal of Cloth and Culture, 7(2), 148-163. https://doi.org/10.2752/175183509X460065

Myzelev, A. (2015). Creating digital materiality: Third-wave feminism, public art, and yarn bombing. Material Culture, 47(1), 58-78.

Nardi, B. A., Schiano, D. J., Gumbrecht, M., \& Swartz, L. (2004). Why we blog. Communications of the ACM The Blogosphere, 47(12), 41-46. https://doi.org/10.1145/1035134.1035163

Papacharissi, Z. (2007). The virtual geographies of social networks: A comparative analysis of Facebook, LinkedIn and ASmallWorld. New Media \& Society, 11(1-2), 199220. https://doi.org/10.1177/1461444808099577

Parkins, W. (2004). Celebrity knitting and the temporality of postmodernity. Fashion Theory, 8(4), 425-442. https://doi.org/10.2752/136270404778051564

Pedersen, S. (2010). Why blog? Motivations for blogging. Oxford: Chandos. https://doi.org/10.1533/9781780631714

Prigoda, E. \& McKenzie, P. (2007). Purls of wisdom: A collectivist study of human information behaviour in a public library knitting group. Journal of Documentation, 63(1), 90-114. https://doi.org/10.1108/00220410710723902

Pöllänen, S. (2013). Homing and downshifting through crafts. In U. Härkönen (Ed.), Reorientation of teacher education towards sustainability through theory and practice (pp. 275-290). Publications of the University of Eastern Finland. Reports and Studies in Education, Humanities, and Theology 7. Joensuu: University of Eastern Finland.

Pöllänen, S. (2015). Elements of crafts that enhance well-being: Textile craft makers' descriptions of their leisure activity. Journal of Leisure Research, 47(1), 58-78. https://doi.org/10.1080/00222216.2015.11950351

Pöllänen, S., \& Voutilainen, L. (2017). Crafting well-being: Meanings and intentions of stay-at-home mothers' craft-based leisure activity. Leisure Sciences, 40(6), 617-633. https://doi.org/10.1080/01490400.2017.1325801

O’Donald, S., Hatza, N., \& Springgay, S. (2010). The knitivism club: Feminist pedagogies of touch. In B. Shultz, J. Sandlin, \& J. Burdick (Eds.) Public pedagogy: Education and learning beyond schooling (pp. 327333). New York, NY: Routledge.

Onwuegbuzie, A. J., \& Johnson, R. B. (2006). The validity issues in mixed research. Research in the schools, 3(1), 48-63.

Orton-Johnson, K. (2014). Knit, purl and upload: new technologies, digital mediations and the experience of leisure. Leisure Studies, 33(3), 305-321. https://doi.org/10.1080/02614367.2012.723730

Riley, J. (2008). Weaving an enhanced sense of self and a collective sense of self through creative textilemaking. Journal of Occupational Science, 15(2), 63-73. https://doi.org/10.1080/14427591.2008.9686611

Riley, J., Corkhill, B., \& Morris, C. (2013). The benefits of knitting for personal and social wellbeing in adulthood: Findings from an international survey. The British Journal of Occupational Therapy, 76(2), 5057. https://doi.org/10.4276/030802213X13603244419077

Rosner, D. K. \& Ryokai, K. (2009). Reflections on craft: probing the creative process of everyday knitters. Proceedings of the seventh ACM conference on Creativity and cognition, C6C'09, Berkeley, USA. New York, NY: ACM, 195-204. https://doi.org/10.1145/1640233.1640264 
Rusiñol-Rodriguez, J., Rodriguez-Bailon, M., \& Ramon-Aribau, A. (2020). Knitting with and for others. Repercussions on motivation. Clothing and Textiles Research Journal, First Online October 28. https://doi.org/10.1177/0887302X20969867

Schaap, F. (2004). Link, lives, logs: Presentation in the Dutch blogosphere. In L. J. Gurak, S. Antonijevic, L. Johnson, C. Ratliff, \& J. Reyman (Eds.) Into the blogosphere: Rhetoric, community, and culture of weblogs. Retrieved from https://hdl.handle.net/11299/172811

Schmidt, J. (2007). Blogging practices: An analytical framework. Journal of Computer-Mediated Communication, 12(June), 1409-1427. https://doi.org/10.1111/j.1083-6101.2007.00379.x

Schofield-Tomschin, S., \& Littrell, M. A. (2001). Textile handcraft guild participation: A conduit to successful aging. Clothing and Textiles Research Journal, 19(2), 41-51. https://doi.org/10.1177/0887302X0101900201

Springgay, S. (2010). Knitting as an aesthetic of civic engagement: Re-conceptualizing feminist pedagogy through touch. Feminist Teacher, 20(2), 111-123. https://doi.org/10.5406/femteacher.20.2.0111

Stannard, C. R., \& Sanders, E. A. (2015). Motivations for participation in knitting among young women. Clothing and Textiles Research Journal, 33(2), 99-114. https://doi.org/10.1177/0887302X14564619

Stebbins R. A. (2015). The serious leisure perspective. In R. A. Stebbins (Ed.) Leisure and positive psychology: Linking activities with positiveness (pp. 11-40). London: Palgrave Macmillan. https://doi.org/10.1007/978-1137-56994-3_2

Teddlie, C., \& Tashakkori, A. (2009). Foundations of mixed methods research: Integrating quantitative and qualitative approaches in the social and behavioral sciences. Thousand Oaks, CA: Sage.

Thomas, D. R. (2003). A general inductive approach for qualitative data analysis. American Journal of Evaluation, 27(2), 237-246. https://doi.org/10.1177/1098214005283748

Torrey, C., Churchill, E., \& McDonald, D. (2009). Learning how: The search for craft knowledge on the Internet. Proceedings of the 27th International Conference on Human Factors in Computing Systems, CHI'09, Boston, USA. New York, NY: ACM, 1371-1380. https://doi.org/10.1145/1518701.1518908

Trammell, K. D., Tarkowski, A., Hofmokl, J., \& Sapp, A. M. (2006). Rzeczpospolita blogów [Republic of Blog]: Examining Polish bloggers through content analysis. Journal of Computer-Mediated Communication, 11(3), 702-722. https://doi.org/10.1111/j.1083-6101.2006.00032.x

Turney, J. (2009). The culture of knitting. Oxford: Berg.

Waterhouse, J. (2010). Indie craft. London: Laurence King Publishing.

Wei, C. (2004). Formation of norms in a blog community. In L. J. Gurak, S. Antonijevic, L. Johnson, C. Ratliff, \& J. Reyman (Eds.) Into the blogosphere: Rhetoric, community, and culture of weblogs. Retrieved from http://blogs.ubc.ca/ewayne/files/2010/03/A-Genre-Analysis-of-the-weblog.pdf

Winge, T. M., \& Stalp, M. C. (2013). Nothing says love like a skull and crossbones tea cozy: Crafting contemporary subversive handcrafts. Craft Research, 4(1), 69-82. https://doi.org/10.1386/crre.4.1.73 1

Wolf, M., \& McQuitty, S. (2011). Understanding the do-it-yourself consumer: DIY motivations and outcomes. Academy of Marketing Science Review, 1(3-4), 154-170. https://doi.org/10.1007/s13162-011-0021-2

Ph.D. Katja Vilhunen is a craft teacher in the city of Kuopio. Her research interests include craft on social media and on the sense of community among craft makers in a online community.

Ph.D. Sinikka Pöllänen is a Professor of craft science in Craft Teacher Education programme at the University of Eastern Finland. Her major research interests include, but are not limited to, crafts and wellbeing, pedagogical models, and learning in authentic contexts. She has published several articles relating to meanings of crafts as an occupation and leisure activity, as well as craft pedagogy and sustainable crafts.

Harri Pitkäniemi, PhD, docent, works as an university lecturer at the School of Applied Educational Science and Teacher Education, at the University of Eastern Finland, Joensuu. His work encompasses a wide variety of perspectives on school learning such as teacher cognition and beliefs, student cognition, and classroom interaction. He also favours comprehensive and integrative methodologies such as mixed methods and research designs which connect a variety of perspectives within a single study. 